\title{
Importance of differentiating Orbicella reefs from gorgonian plains for ecological assessments of Caribbean reefs
}

\author{
Stacey M. Williams ${ }^{1,2, *}$, Peter J. Mumby ${ }^{3,4}$, Iliana Chollett ${ }^{3,4}{ }^{\text {, Jorge Cortés }}{ }^{1}$ \\ ${ }^{1}$ Centro de Investigación en Ciencias del Mar y Limnología, Universidad de Costa Rica, San Pedro, 11501-2060 San José, \\ Costa Rica \\ ${ }^{2}$ Institute for Socio-Ecological Research (ISER), PO Box 3151, 00667-3151 Lajas, Puerto Rico \\ ${ }^{3}$ Marine Spatial Ecology Lab, College of Life and Environmental Sciences, University of Exeter, Exeter EX4 4PS, UK \\ ${ }^{4}$ Marine Spatial Ecology Lab, School of Biological Sciences, University of Queensland, St. Lucia, Queensland 4072, Australia
}

\begin{abstract}
Region-wide assessments of coral cover typically rely on meta-analyses of smallscale ecological studies which have combined different coral reef habitats. This is particularly problematic on forereefs where at least 2 habitats can be found; coral-based bioherms and colonized hardgrounds (hereafter Orbicella reefs and gorgonian plains), each with very different structure and scleractinian coral cover. Here, we quantify the degree to which the failure to differentiate forereef zones dominated by framework building corals, mainly Orbicella spp. (hereafter Orbicella reefs) from gorgonian plains can lead to biased assessments of coral cover. We also provide a baseline of an extensive sample of Caribbean coral reefs in 2010-2012 for the 2 habitats within the forereef. Mean scleractinian coral cover $( \pm \mathrm{SE})$ at Orbicella reefs was $24 \pm 1.3 \%$, more than double the coral cover found on the gorgonian plains $(10 \pm 1.6 \%)$. The difference in coral cover between habitats within the same geomorphological zone is consistent with those calculated from an independent dataset for the basin (Atlantic and Gulf Rapid Reef Assessment). Furthermore, the average coral cover calculated for Caribbean Orbicella reefs was more than double the values previously reported for entire reefs in the region a decade ago $(10 \%)$, which integrated data from different habitats, depths, time periods and surveyors. Differentiating between forereef habitats has provided a meaningful baseline of coral state, which allows for realistic targets for management in the Caribbean basin.
\end{abstract}

KEY WORDS: Coral · Forereef habitats · Orbicella reefs · Gorgonian plains $\cdot$ Caribbean $\cdot$ AGRRA

\section{INTRODUCTION}

Caribbean coral reefs have changed dramatically in the last 5 decades (Jackson et al. 2014); the abundance of reef-associated organisms, especially corals and fishes, have suffered massive declines through hurricanes, disease outbreaks, bleaching, pollution, sedimentation and overfishing (Hughes 1994, Aronson \& Precht 2001, Kramer 2003, Weil et al. 2006, Paddack et al. 2009). A number of studies have quan- tified the state of Caribbean reefs at a regional scale and, in some cases, their trajectory (Gardner et al. 2003, Côté et al. 2005, Bruno et al. 2009, Schutte et al. 2010, Jackson et al. 2014). Regional assessments allow a benchmark to be set against which individual reefs can be compared in space and time, quantifying regional trends (Jackson et al. 2014) and comparing different regions to identify the drivers of largescale differences (Roff \& Mumby 2012). Most regional assessments have used meta-analysis to integrate 
the results of multiple studies carried out by different surveyors, usually with different objectives in mind. An exception has been the analysis of regionally standardized survey methodologies, such as the Atlantic and Gulf Rapid Reef Assessment (AGRRA) (Kramer 2003), although this too suffers from the issue of multiple surveyors and habitat types, as well as some methodological inconsistencies that increase the variability in the data (e.g. variable sampling effort, haphazardly located transects) (Kramer 2003).

Regional meta-analyses have been shown to be robust to common inconsistencies among data, such as variable survey methodology (Côté et al. 2005), however they cannot account for inconsistencies that have not been recorded. In particular, it is typically assumed that reefs can be grouped by major reef zone (e.g. patch reef, backreef, forereef) and depth. Yet, forereef environments, which can be identified by their geomorphology (Andréfouët et al. 2006), comprise at least 2 contrasting habitats even at the same depth. The first are true coral habitats that were generally built by the major framework-building corals Orbicella spp. and some species of acroporids (Goreau 1959, Geister 1977, Mumby \& Harborne 1999). These habitats, hereafter Orbicella reefs, can be structurally complex and usually possess high diversity and density of species, while also supporting the most significant ecosystem services, which include cultural, educational and fishery services (Mumby et al. 2008, Harborne 2009). The second are 'gorgonian plains' (Mumby \& Harborne 1999, Mumby 2014), also known as hardgrounds, which are relatively featureless, flat pavement that typically possesses very low relief and is dominated by octocorals. Gorgonian plains are usually located in more exposed environments (Burke 1982, Torres et al. 2001), and have very little scleractinian coral, likely because higher exposure resuspends sediments near the benthos, providing an unstable substrate for recruitment. However, octocorals, the predominant benthic invertebrates on this habitat, are more resilient to fluctuating habitats (Opresko 1973) and commonly recruit and survive in areas with water movement (Barham \& Davies 1968, Yoshioka \& Yoshioka 1989). Few empirical studies identify habitat type explicitly and, with the exception of CARICOMP (Caribbean Coastal Marine Productivity Program) (CARICOMP 2002), most regional survey methodologies, including AGRRA, combine all forereef habitats together during analyses. Regional assessments of coral reef condition have therefore potentially combined hardbottom habitats that are naturally characterized by low coral cover with coral-based bioherms.
Such confounding would tend to reduce the average coral cover by including sites that lack and have always lacked high abundance of coral, in an unbalanced design through time and space (i.e. proportion of sites per habitat is unlikely to be the same), which would therefore add noise to the signal and obscure spatial and temporal patterns within the basin.

Recent advances with remote sensing have now made it possible to discriminate Orbicella reefs from gorgonian plains at a large scale. Several techniques are available, including the use of acoustic sensors that detect the roughness and hardness of the seabed (Bejarano et al. 2010, 2011), as well as measures of wave exposure, which have been shown to accurately $(81 \%)$ discriminate Orbicella reefs from gorgonian plains within the forereef, given that gorgonian plains thrive in heavily exposed environments (Chollett \& Mumby 2012). Wave exposure can be obtained using only information on the configuration of the coastline and prevailing wind speed and direction, representing a cheap alternative for the largescale mapping of forereef habitats (Chollett \& Mumby 2012). In the present study, one of our major goals was to assess the impact of confounding forereef habitats on average scleractinian coral cover using a dataset gathered by the FORCE (Future of Reefs in a Changing Environment) project, collected with the same methods and surveyors in 12 countries in the Caribbean. We validated our results with an independent dataset available for the region, AGRRA, and put our results into context by comparing our estimates of current scleractinian coral cover to other regional studies (Gardner et al. 2003, Jackson et al. 2014).

\section{MATERIALS AND METHODS}

\section{Data collection (FORCE)}

Coral reef benthic communities were surveyed from 2010 to 2012 in 12 countries: Honduras, Belize, Curaçao, Bonaire, Jamaica, Barbados, Dominican Republic, Antigua, St. Lucia, St. Vincent and the Grenadines, Costa Rica and Panamá (Fig. 1). Sites within the forereef according to geomorphological maps produced by the Millennium Coral Reef Mapping project (Andréfouët et al. 2006), were selected using the 'generate random points' tool of the Hawth Tools program in ArcGIS 9.2 (ESRI 2009). Sites were assessed in situ and defined as having a homogeneous habitat within a spatial extent of at least $200 \times 200 \mathrm{~m}$. Originally, we set our experimental design to assess the current state 


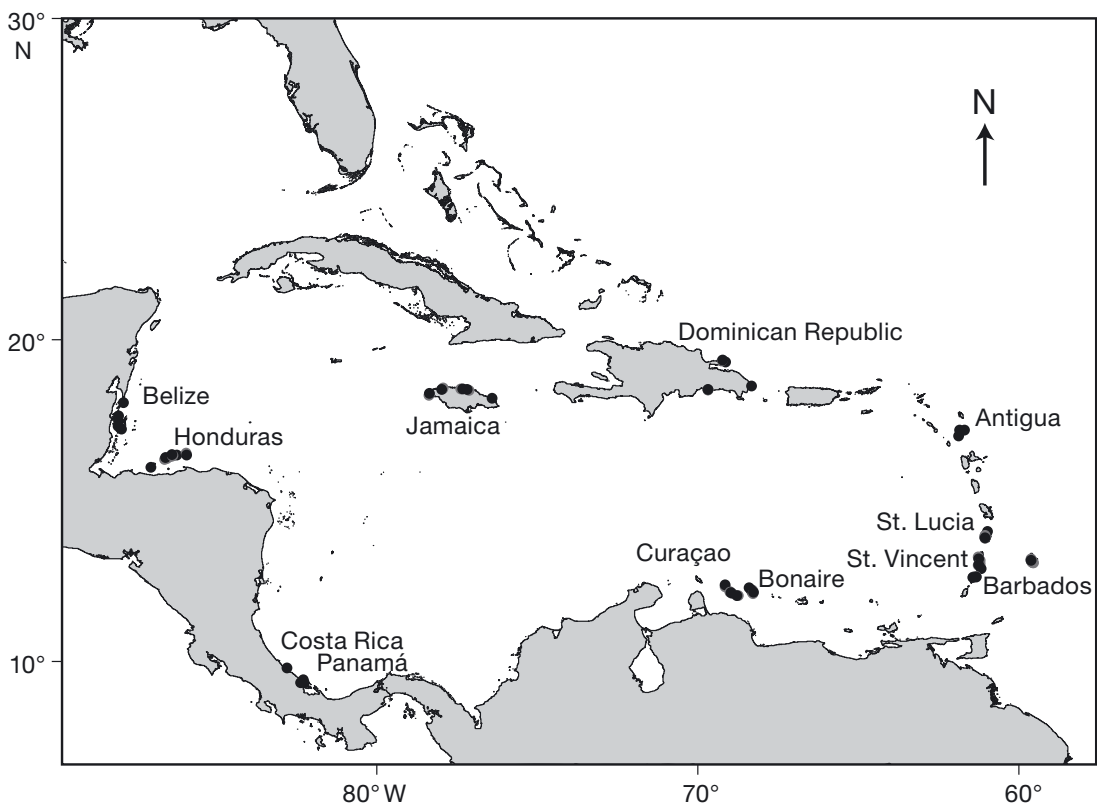

Fig. 1. Location of study sites $(\bullet)$ surveyed in 12 Caribbean countries fore transects from the different depth zones were pooled for further statistical analyses. At each site, benthic communities were assessed on 6 randomly placed $10 \mathrm{~m}$ transect lines which were set parallel to the coastline. Scleractinian coral cover was measured using the point intercept method and corals were identified to species level and recorded every $10 \mathrm{~cm}$. There are some shortcomings to using point intercept technique, in that coral cover estimate may be lower in habitats that are characterized by small coral colonies, common on gorgonian plains.

To assess the sufficiency of our sampling given the sample size, the margin of error in coral cover was calculated for each forereef habitat. The margins of error were moderate, with a median of $4 \%$ for gorgonian plains and $6 \%$ for Orbicella reefs.

\section{Statistical analysis}

\section{Habitat differences (FORCE data)} of sites per habitat is not balanced among countries (Table 1). This shortcoming has been taken into account in the statistical analyses (see following subsection). Surveys were conducted at 92 Orbicella reefs (Fig. 2a) and at 28 gorgonian plains (Fig. 2b) at 10-15 m depths with the exception of Honduras and Belize where surveys were conducted at 5-10 $\mathrm{m}$ and 15-20 m (Table 1). Coral cover did not vary significantly between depths in Honduras and Belize, there-

Table 1. Sampling design including the number of Orbicella reefs and gorgonian plains, depth, sampling month and year for each country surveyed during this study

\begin{tabular}{|lcccc|}
\hline Country & $\begin{array}{c}\text { Orbi- } \\
\text { cella }\end{array}$ & $\begin{array}{c}\text { Gorgo- } \\
\text { nian }\end{array}$ & $\begin{array}{c}\text { Depth } \\
(\mathrm{m})\end{array}$ & $\begin{array}{c}\text { Sampling } \\
\text { date }\end{array}$ \\
\hline Antigua (ANT) & 3 & 5 & $10-15$ & Jul 2011 \\
Barbados (BAR) & 8 & 0 & $10-15$ & Mar 2011 \\
Belize (BEL) & 5 & 10 & $5-10,15-20$ & Nov 2010 \\
Bonaire (BON) & 7 & 0 & $10-15$ & Jan 2011 \\
Costa Rica (CR) & 0 & 8 & $10-15$ & Apr 12 \\
Curaçao (CUR) & 8 & 0 & $10-15$ & Jan 2011 \\
Dominican Republic (DR) & 7 & 7 & $10-15$ & Jun 2011 \\
Honduras (HON) & 11 & 3 & $5-10,15-20$ & Oct 2010 \\
Jamaica (JAM) & 11 & 0 & $10-15$ & Feb 2011 \\
Panamá (PAN) & 8 & 0 & $10-15$ & Apr 2012 \\
St. Lucia (STL) & 7 & 1 & $10-15$ & Jul 2011 \\
St. Vincent and Grenadines (SVG) & 12 & 3 & $10-15$ & Aug 2011 \\
\hline
\end{tabular}

To test whether combining forereef habitat types skewed coral cover estimate in the Caribbean basin and within individual countries, we used generalized linear mixed models (GLMM) (Bolker et al. 2009) using the lme4 package (Bates et al. 2014) in R. We identified the effects of forereef habitat on the cover of coral using the entire FORCE dataset. Coral cover was the response variable, while habitat was treated as the fixed factor and sites and countries were random, with sites nested within countries. To select the optimal structure of the the first with no random term and the second with the random component using site nested in country. The optimal model was chosen based on the lowest Akaike's information criteria (AIC) value. We used Poisson distributions, given that the response variable was a proportion (percentage of coral), and estimated the parameters with Laplace approximations because there were fewer than 5 random variables (Breslow \& Clayton 1993) for random component, we ran 2 models, 

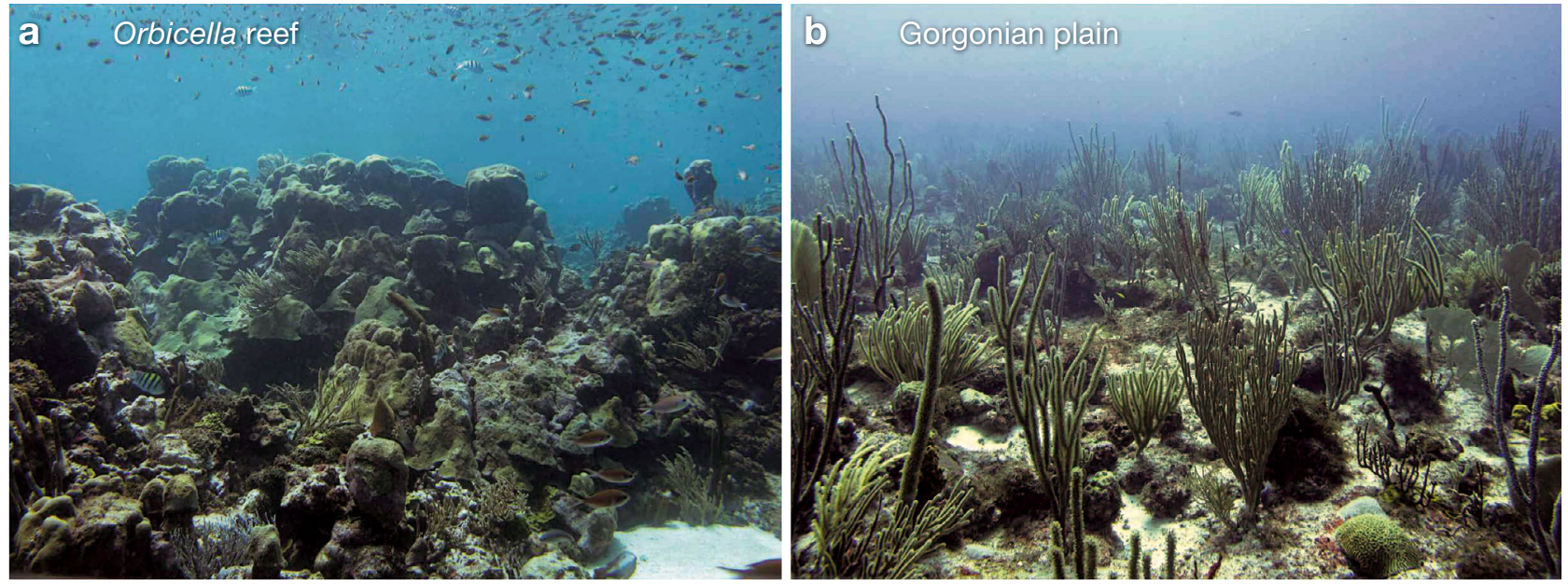

Fig. 2. Contrasting Caribbean coral forereef habitats: (a) Orbicella reefs and (b) gorgonian plains

GLMMs. The optimal model was validated by plotting the residuals against the fitted values and using a quantile-quantile plot. Significance levels (p-values) were obtained from $Z$ tests (Zuur et al. 2009).

\section{Consistency of results (AGRRA data)}

To confirm the differences in coral cover between habitats observed in the FORCE results, we repeated the analysis using the AGRRA (www.agrra.org) dataset. As a conservative measure we included prebleaching data (2005), therefore focusing on benthic surveys carried out between 1998 and 2011. Many sites in the AGRRA database have repeated measurements; therefore, we used the most current year of data for each site.

The AGRRA dataset includes a variety of habitat types; therefore, data were extracted from forereef habitats and further classified as Orbicella reefs and gorgonian plains using the method described by Chollett \& Mumby (2012). We calculated the probability of occurrence of Orbicella reefs within forereef zones given a predictive binomial model that uses wave exposure as a sole predictor of habitat (Chollett \& Mumby 2012); wave exposure values were extracted for each AGRRA site at a $50 \mathrm{~m}$ spatial resolution for the Mesoamerican Barrier Reef (Chollett \& Mumby 2012), and a $1 \mathrm{~km}$ spatial resolution for the rest of the Caribbean (Chollett et al. 2012). Predicting habitat type from wave exposure has shown to be accurate $(81 \%)$ at a spatial resolution of $50 \mathrm{~m}$ (Chollett \& Mumby 2012); however, the accuracy of the method is unknown when data at a lower spatial res- olution are used. Therefore, we tested the accuracy of the $1 \mathrm{~km}^{2}$ spatial resolution data on predicting habitat type using the FORCE dataset and permutation analysis. Orbicella reefs and gorgonian plains were misclassified 23 and $12 \%$ (respectively) of the time with FORCE surveys, indicating that the accuracy of the predictive model is adequate at the spatial resolution for the assignment of habitat to the AGRRA data $\left(1 \mathrm{~km}^{2}\right)$. To acknowledge the uncertainty in habitat assignment in further analyses, we resampled the AGRRA dataset, and the mean coral cover reported is based on the propagated errors, i.e. the mean and standard errors were calculated from 100 permutations of samples, whereby $12 \%$ of the samples (randomly selected from gorgonian plains data) were replaced with data from randomly selected Orbicella reef coral cover. This procedure was repeated for Orbicella reefs, replacing $23 \%$ of the samples.

Within- and between-country comparisons (FORCE data)

Given the unbalanced design of the dataset, we assessed the variation in coral cover between the forereef habitats in countries where data existed for both habitats: Antigua (ANT), Belize (BEL), Dominican Republic (DR), Honduras (HON), and St. Vincent and Grenadines (SVG). We used a GLMM test to identify the effects of forereef habitat on coral cover within a particular country. Coral cover was the response variable, whilst country and habitat were fixed variables, and site was the random variable. Subsequently, we 
tested the interaction between country and habitat, with site as a random variable. The relevance of the random component was assessed by comparing the 2 models described above. Model distributions and procedures for model selection, validation, and obtaining $\mathrm{p}$-values were identical to those used in GLMMs for testing habitat differences (see 'Habitat differences [FORCE data]').

\section{RESULTS}

\section{Habitat differences (FORCE data)}

Coral cover was significantly greater (GLMM; p $<0.0001)$ on Orbicella reefs $(24 \pm 1.3 \%$, mean \pm $\mathrm{SE}$ ) than on gorgonian plains $(10 \pm 1.6 \%)$ (Table 2 ). We observed the random effects (site nested in country, country) to be significant ( $p<0.0001)$; standard errors of the random effects were 0.41 and 0.22 , while variances were 0.17 and 0.05 for site nested in country and country, respectively. The frequency distribution of coral cover was skewed for both the habitats, whereby the median scleractinian coral cover on Orbicella reefs was $23 \%$, more than double that of gorgonian plains (9\%). Because Orbicella sites dominated the dataset, the overall average cover on both habitats was modestly high, at $20 \pm 0.5 \%$. Maximum recorded coral cover was $22.3 \%$ on gorgonian plains and $44.1 \%$ on Orbicella reefs (Fig. 3). Sixty-seven percent of gorgonian plain sites exhibited a coral cover $\leq 10 \%$, while $55 \%$ of Orbicella reefs comprised a coral cover $>20 \%$.

Table 2. Effects of forereef habitat (Habitat) on coral cover in the Caribbean region observed in the FORCE dataset using a generalized linear mixed effect model (GLMM). The model presented was the optimal model, which included random effects. Therefore, habitat was categorized as a fixed factor, and country and site were random variables, with site nested within country

\begin{tabular}{|llrrrr|}
\hline FORCE: Coral cover & Estimate & $\mathrm{SE}$ & $Z$-value & p-value \\
\hline $\begin{array}{l}\text { Fixed } \\
\text { effects }\end{array}$ & Intercept & 3.08 & 0.08 & 38.56 & $<0.0001$ \\
& & -0.81 & 0.12 & -6.94 & $<0.0001$ \\
& & Variance & $\mathrm{SD}$ & $Z$-value & p-value \\
\hline Random & Site (Country) & 0.17 & 0.41 & & $<0.0001$ \\
effects & Country & 0.05 & 0.22 & & $<0.0001$ \\
AIC: 5967.6 & & & & \\
\hline
\end{tabular}

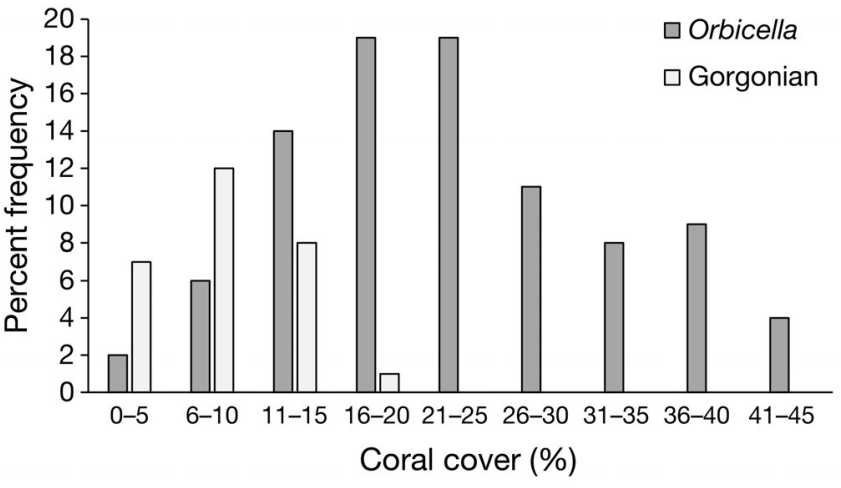

Fig. 3. Frequency distribution of coral cover in Orbicella reefs and gorgonian plains for all 12 countries

\section{Consistency of results (AGGRA data)}

We used AGRRA data in order to assess the consistency of the results observed in the FORCE GLMM model, therefore testing the significance of the fixed factor (habitat) and random factors (site nested in country). The entire AGRRA dataset includes a variety of habitat types, with $22 \%$ of the sites (673 in total) characterized as Orbicella reefs and $78 \%$ as gorgonian plains. As observed with the FORCE data (see Table 2), coral cover significantly differed between forereef habitats within the AGRRA data (GLMM; p = 0.0001) (Table 3), with mean coral cover $( \pm \mathrm{SE})$ on AGRRA Orbicella sites being $19.2 \pm 0.04 \%$, while the average at gorgonian plains was $14.8 \pm 0.05 \%$. We observed the random effects (site nested in country, country) to be significant $(p=0.0001)$ in the model; standard errors of the

Table 3. Cross-validation of the FORCE generalized linear mixed effect model (GLMM) using the entire AGRRA dataset (1998-2011). The structure of the model was the same as Table 2; coral cover was the response variable, habitat was the fixed variable and random effects were site nested in country, and country

\begin{tabular}{|llcccr}
\hline AGRRA: Coral cover & Estimate & SE & Z-value & p-value \\
\hline $\begin{array}{l}\text { Fixed } \\
\text { effects }\end{array}$ & Intercept & 5.02 & 0.07 & 66.97 & $<0.0001$ \\
& & 0.19 & 0.05 & 3.81 & 0.0001 \\
& Variance & SD & Z-value & p-value \\
\hline Random & Site (Country) & 0.29 & 0.54 & $<0.0001$ \\
effects & Country & 0.08 & 0.29 & $<0.0001$ \\
AIC: 7835.8 & & & & \\
\hline
\end{tabular}


random effects were 0.54 and 0.29 , while variances were 0.29 and 0.08 for site nested in country and country, respectively.

\section{Within- and between-country comparisons (FORCE data)}

The highest mean coral cover $( \pm$ SE) on Orbicella reefs was recorded in Bonaire $(33.9 \pm 1.7 \%)$, Panamá $(31.7 \pm 1.4 \%)$, and Barbados $(29.8 \pm 1.7 \%)$, while the lowest was observed at Antigua (11.7 $\pm 1.5 \%)$, Jamaica $(16.7 \pm 0.9 \%)$, and St. Lucia $(17.1 \pm 1.4 \%)$ (Fig. 4). For gorgonian plains, the highest mean coral cover was recorded in Belize (14.6 $\pm 1.2 \%)$ and Dominican Republic $(14.3 \pm 1.8 \%)$ and the lowest cover was in St. Vincent and Grenadines (6.2 \pm $1.3 \%)$, Honduras $(7.0 \pm 1.2 \%)$ and Costa Rica (7.7 \pm $1.0 \%$ ) (Fig. 4). We then assessed the variation in coral cover between the forereef habitats in individual countries where data were available (ANT, BEL, DR, HON, SVG). The random variable, site, was significant $(\mathrm{p}=0.0001)$ in both the main and interaction model (Table 4). As seen in the interaction model, the difference in coral cover between the 2 forereef habitats was insignificant in Antigua and Belize (Table 4). In contrast, coral cover was significantly greater on Orbicella reefs when compared to gorgonian plains in Dominican Republic, Honduras and St. Vincent and the Grenadines (Table 4). Coral cover on Orbicella reefs in Honduras and St. Vincent and Grenadines was 19.9 and $15.9 \%$ greater, respectively, than cover on gorgonian plains (Fig. 4).
Table 4. Effects of forereef habitat (Habitat), country (see Table 1 for abbreviations) and interaction of habitat (Gorg = gorgonian plains, Orb = Orbicella reefs) and country on coral cover in individual countries where data were available for both habitats using a generalized linear mixed effect model (GLMM) and as observed in the FORCE dataset. Country and habitat were categorized as fixed factors and site as a random variable. Bold indicates significant interaction terms

\begin{tabular}{|c|c|c|c|c|c|}
\hline \multicolumn{2}{|c|}{ FORCE: Coral cover } & \multirow{2}{*}{$\begin{array}{c}\text { Estimate } \\
2.64\end{array}$} & \multirow{2}{*}{$\begin{array}{c}\text { SE } \\
0.18\end{array}$} & \multirow{2}{*}{$\begin{array}{c}Z \text {-value } \\
14.65\end{array}$} & \multirow{2}{*}{$\begin{array}{l}\mathrm{p} \text {-value } \\
<0.0001\end{array}$} \\
\hline Fixed & Intercept & & & & \\
\hline \multirow{6}{*}{ effects } & BEL & 0.53 & 0.20 & 2.60 & 0.009 \\
\hline & DR & 0.54 & 0.21 & 2.58 & 0.01 \\
\hline & $\mathrm{HON}$ & 0.51 & 0.20 & 2.47 & 0.014 \\
\hline & SVG & 0.28 & 0.20 & 1.38 & 0.167 \\
\hline & Habitat & -0.72 & 0.12 & -5.92 & $<0.0001$ \\
\hline & & Variance & $\mathrm{SD}$ & $Z$-value & p-value \\
\hline $\begin{array}{l}\text { Random } \\
\text { effects }\end{array}$ & Site & 0.16 & 0.39 & & \\
\hline \multicolumn{6}{|c|}{$\mathrm{AIC}=2979.3$} \\
\hline Fixed & Intercept & 2.39 & 0.20 & 11.68 & $<0.0001$ \\
\hline \multirow[t]{9}{*}{ effects } & Gorg $\times$ ANT & -0.21 & 0.29 & -0.73 & 0.464 \\
\hline & Orb $\times$ BEL & 0.49 & 0.26 & 1.93 & 0.054 \\
\hline & Gorg $\times$ BEL & 0.25 & 0.24 & 1.03 & 0.303 \\
\hline & Orb $\times$ DR & 0.73 & 0.23 & 3.12 & 0.002 \\
\hline & Gorg $\times$ DR & 0.24 & 0.29 & 0.85 & 0.394 \\
\hline & Orb $\times \mathrm{HON}$ & 0.89 & 0.23 & 3.89 & 0.0001 \\
\hline & Gorg $\times \mathrm{HON}$ & J -0.51 & 0.30 & -1.74 & 0.082 \\
\hline & Orb $\times$ SVG & 0.63 & 0.23 & 2.77 & 0.006 \\
\hline & Gorg $\times$ SVG & -0.62 & 0.30 & -2.09 & 0.037 \\
\hline $\begin{array}{l}\text { Random } \\
\text { effects }\end{array}$ & Site & 0.22 & 0.33 & & 0.0001 \\
\hline $\mathrm{AIC}=2967$ & & & & & \\
\hline
\end{tabular}

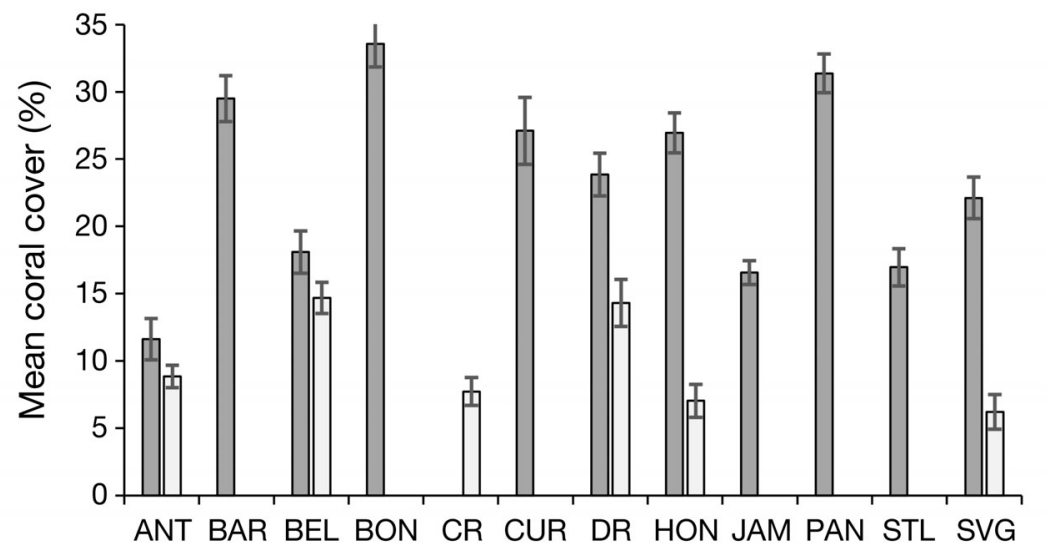

$\square$ Orbicella $\quad \square$ Gorgonian

Fig. 4. Coral cover (mean \pm SE) on Orbicella reefs and gorgonian plains in the 12 countries around the Caribbean. See Table 1 for country abbreviations

\section{DISCUSSION}

Our Caribbean-wide analysis shows that combining habitats that are characterized by low coral cover (gorgonian plain) with those habitats that have significant reef development (Orbicella reef), can produce biased estimates of coral cover. In both the FORCE and AGRRA datasets, coral cover at Orbicella reefs was significantly different and greater than at gorgonian plains. Combining habitats resulted in an underestimation of mean coral cover by $12 \%$, when using consistent methods and surveyors. Since Orbicella sites dominated the FORCE dataset, the overall cover $( \pm \mathrm{SE})$ on both habitats was modestly high at $20 \% \quad( \pm 0.5)$. Therefore, when combining results from multiple studies, the exact value 
would depend on the relative abundance of Orbicella reefs vs. gorgonian plains in the particular study. Our overall estimates of coral cover on Orbicella reefs were based on extensive sampling from multiple countries in the Caribbean. However, we did not sample all physical environments in the Caribbean (Chollett et al. 2012) and therefore the regional representativeness of the dataset is impossible to assess.

Gardner et al. (2003) estimated 10\% coral cover for 263 reefs in the Caribbean in 2001, but less than $6 \%$ of the Orbicella sites surveyed in the FORCE study fell at or below this value. The Gardner et al. (2003) meta-analysis included data that was collected by different observers using contrasting monitoring methods and at different reef zones/habitats, depths, and collection times. After identifying the habitats included in Gardner et al. (2003), we found that $77 \%$ of sites were forereef habitats, and based on wave exposure regime (Chollett \& Mumby 2012), only about $27 \%$ of the forereef sites were probably located on Orbicella reefs (Fig. 5), suggesting the inclusion of multiple habitats as a possible cause of low coral cover reported in this region-wide study. In addition, some of the sites included in the meta-analysis could have been collected in Acropora palmata zones which have suffered large declines from white band disease. The differences in coral cover observed cannot be explained by coral recovery because such trends are scarce in the region (Connell 1997, Roff \& Mumby 2012). An alternative explanation of the discrepancy could be geographic bias; however, this seems un- likely to be the main cause of the disparity because our dataset included countries with some of the lowest coral cover in the Caribbean, such as Jamaica.

The most recent regional assessment of coral reef conditions was carried out by Jackson et al. (2014). In support of our findings, their regional coral cover assessment was also considerably higher than the coral cover reported in the Gardner et al. (2003) study. Overall, our coral cover values do not vary far from the values reported in 2014. There are a few exceptions: for example, the coral cover on Barbados and Panamá in our study was double the value reported by Jackson et al. (2014). Disparities between studies can be expected given the differences of locations, time, depth and reef habitat of sites surveyed. However, both studies agree that the reefs in Bonaire are in a better condition compared to those of other countries with highly degraded reefs, such as Antigua, Jamaica, St. Lucia and Belize.

Many reefs in the Caribbean are degraded. However, on $94 \%$ of the Orbicella sites, mean coral cover was well above $10 \%$, a putative level below which reef accretion might fail to outweigh erosion (Perry et al. 2013), while others suggest that positive carbonate budgets are still feasible throughout this century provided that local and global stressors are managed and where coral cover is higher than $20 \%$ (Kennedy et al. 2013). Taking a $20 \%$ coral cover threshold, $64 \%$ of the Orbicella reef sites surveyed meet this target, implying that there is considerable scope for continued ecosystem functioning in the Caribbean. How- a

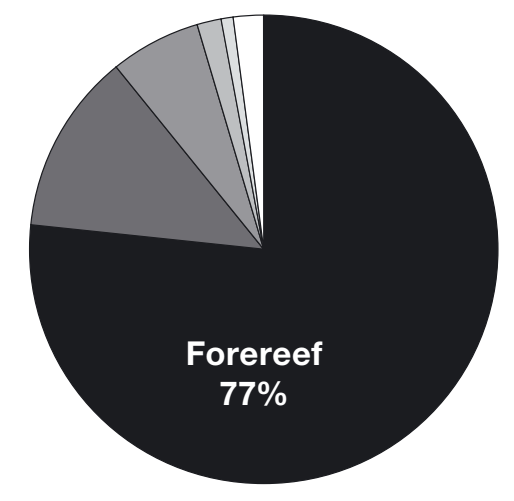

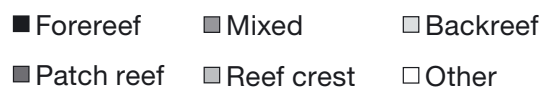

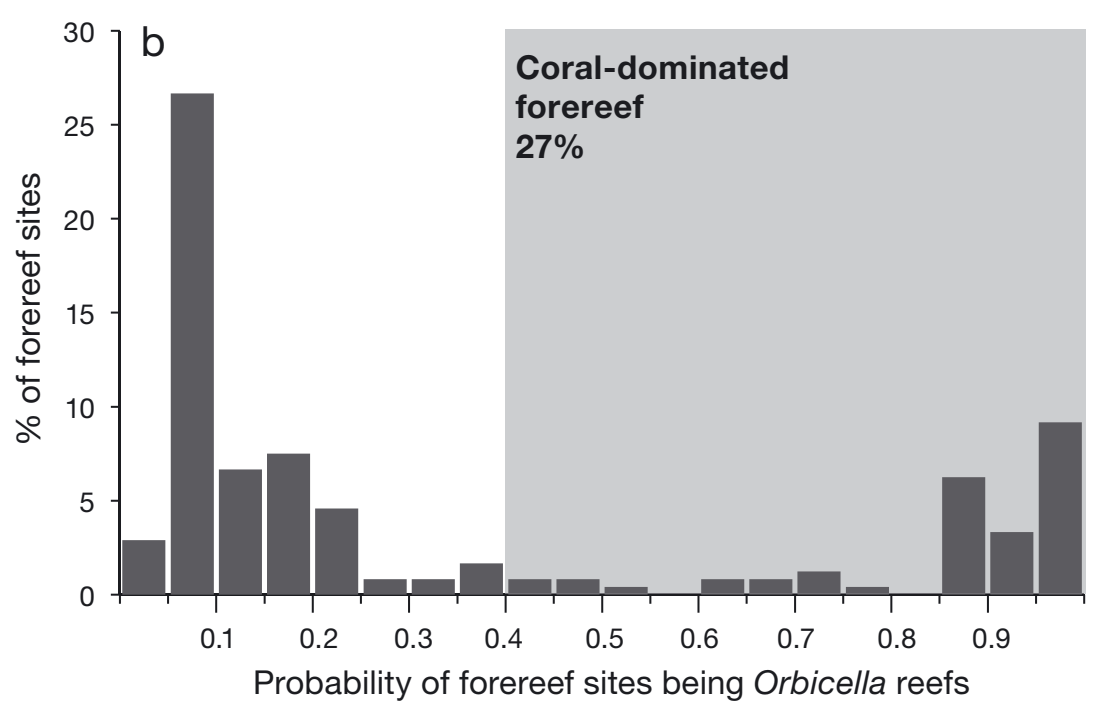

Fig. 5. (a) Distribution of sites assessed by Gardner et al. (2003) per habitat type, (b) frequency distribution of the probability of occurrence of Orbicella reefs within forereef habitats, according to a probability threshold of wave exposure of 0.4 identified by Chollett \& Mumby (2012) 
ever, there are challenges in minimizing both local and global stressors, while also accommodating the resource needs of coastal human populations.

Distinguishing between forereef habitats before any analysis is necessary to report a baseline for future research or monitoring, or to provide data for comparison with earlier surveys. To reduce the likelihood of habitat confounding effects in the future, habitat descriptors provided by in situ assessments or new mapping techniques could be incorporated into monitoring programs such as AGRRA and future regional analyses of reef condition in the basin.

Acknowledgements. This research was supported by a European Union funded project, Future of Reefs in a Changing Environment (FORCE, grant 244161) of the FP7 and the Universidad de Costa Rica (project 808-B0-531) through the Marine Science and Limnology Research Center (CIMAR) and FUNDEVI. We thank the Fisheries Departments, Ministries of the Environment, and individuals who provided permission and assistance in the following countries: Antigua (S. Archibald), Barbados (L. Brewster), Belize (Fisheries: J. Azueta; ERI: L. Cho-Rickets; Reefs End Lodge: Saint), Bonaire (STINAPA: R. de Leon, Dive Friends Bonaire), Costa Rica (Punta Uva Dive Center), Curaçao (CARMABI: M. Vermeij), Dominican Republic (Punta Cana Ecological Foundation: B. Hulefeld, J. Jhell; La Caleta Marine Park: R. Torres; Las Galeras and Superior Divers; Y. Rodríguez), Honduras (Roatán Marine Park: N. Bach; Utila Center of Marine Ecology: S. Box; Reef House Resort; Clearwater Paradise), Jamaica (Montego Bay Marine Park: B. Zane; Lady G' Diver), Panamá (STRI: Smithsonian Institute), St. Lucia (SMMA: T. Nelson; Fisheries: A. Joseph, S. Williams-Peter), and St. Vincent and the Grenadines (Fisheries: Mr. Ryan, C. Isaacs; Tobago Cays Marine Park: O. Harvey; Kings Landing: M. James; G. Adams). We also thank V. Schutte, I. Côté and A. Harborne for offering their datasets, and the editor and 2 reviewers for their comments which greatly improved the manuscript.

\section{LITERATURE CITED}

Andréfouët S, Muller-Karger F, Robinson J, Kranenburg C, Torres-Pulliza D, Spraggins S, Murch B (2006) Global assessment of modern coral reef extent and diversity for regional science and management applications: a view from space. Proc 10th Int Coral Reef Symp, Okinawa, Japan 1732-1745

Aronson RB, Precht WF (2001) White-band disease and the changing face of Caribbean coral reefs. Hydrobiologia 460:25-38

Barham E, Davies J (1968) Gorgonians and water motion studies in Gulf of California. Underwat Nat 5:24-28

Bates D, Maechler M, Bolker B, Walker S (2014) lme4: linear mixed-effects models using Eigen and S4 (R package version 3.1.1). www.cran.r-project.org (accessed July 2014)

Bejarano S, Mumby PJ, Hedley JD, Sothern I (2010) Combining optical and acoustic data to enhance the detection of Caribbean forereef habitats. Remote Sens Environ $114: 2768-2778$
Bejarano S, Mumby PJ, Sotheran I (2011) Predicting structural complexity of reefs and fish abundance using acoustic remote sensing (RoxAnn). Mar Biol 158:489-504

> Bolker BM, Brooks ME, Clark CJ, Geange SW, Poulsen JR, Stevens MHH, White JSS (2009) Generalized linear mixed models: a practical guide for ecology and evolution. Trends Ecol Evol 24:127-135

Breslow NE, Clayton DG (1993) Approximate inference in generalized linear mixed models. J Am Stat Assoc 88: 9-25

Bruno JF, Sweatman H, Precht WF, Selig ER, Schutte VGW (2009) Assessing evidence of phase shifts from coral to macroalgal dominance on coral reefs. Ecology 90: 1478-1484

Burke RB (1982) Reconnaissance study of the geomorphology and benthic communities of the outer barrier reef platform, Belize. In: Rutzler K, Macintyre IG (eds) Smithsonian Contribution to Marine Science 12. Smithsonian Institution, Washington, DC, p 509-526

CARICOMP (2002) Status and temporal trends at CARICOMP coral reef sites. Proc 9th Int Coral Reef Symp, Bali 1:325-330

> Chollett I, Mumby PJ (2012) Predicting the distribution of Montastraea reefs using wave exposure. Coral Reefs 31: 493-503

Chollett I, Mumby PJ, Müller-Karger FE, Hu C (2012) Physical environments of the Caribbean Sea. Limnol Oceanogr 57:1233-1244

Connell JH (1997) Disturbance and recovery of coral assemblages. Coral Reefs 16:S101-S113

Côté IM, Gill JA, Gardner TA, Watkinson AR (2005) Measuring coral reef decline through meta-analyses. Philos Trans R Soc Lond B 360:385-395

ESRI (2009) ArcMap 9.2. ESRI, Redlands, CA

> Gardner TA, Côté IM, Gill JA, Grant A, Watkinson AR (2003) Long-term region-wide declines in Caribbean corals. Science 301:958-960

Geister J (1977) The influence of wave exposure on the ecological zonation of Caribbean coral reefs. Proc 3rd Int Coral Reef Symp, Miami 1:23-29

- Goreau TF (1959) The ecology of Jamaican coral reefs. I. Species composition and zonation. Ecology 40:67-90

$>$ Harborne AR (2009) First among equals: why some habitats should be considered more important than others during marine reserve planning. Environ Conserv 36: $87-90$

> Hughes TP (1994) Catastrophes, phase shifts, and large-scale degradation of a Caribbean coral reef. Science 265: 1547-1551

Jackson JBC, Donovan MK, Cramer KL, Lam W (2014) Status and trends of Caribbean coral reefs: 1970-2012. Global Coral Reef Monitoring Network, IUCN, Gland

> Kennedy EV, Perry CT, Halloran PR, Iglesias-Prieto R and others (2013) Avoiding coral reef functional collapse requires local and global action. Curr Biol 23:912-918

> Kramer PA (2003) Synthesis of coral reef health indicators for the Western Atlantic: results of the AGRRA program (1997-2000). Atoll Res Bull 496:1-58

Mumby PJ (2014) Stratifying herbivore fisheries by habitat to avoid ecosystem overfishing of coral reefs. Fish Fish, doi:10.1111/faf.12078

Mumby PJ, Harborne AR (1999) Development of a systematic classification scheme of marine habitats to facilitate regional management and mapping of Caribbean coral reefs. Biol Conserv 88:155-163 
Mumby PJ, Broad K, Brumbaugh DR, Dahlgren CP and others (2008) Coral reef habitats as surrogates of species, ecological functions, and ecosystem services. Conserv Biol 22:941-951

Opresko DM (1973) Abundance and distribution of shallowwater gorgonians in the area of Miami, Florida. Bull Mar Sci 23:535-558

Paddack MJ, Reynolds JD, Aguilar C, Appeldoorn RS and others (2009) Recent region-wide declines in Caribbean reef fish abundance. Curr Biol 19:590-595

Perry CT, Murphy GN, Kench PS, Smithers SG, Edinger EN, Steneck RS, Mumby PJ (2013) Caribbean-wide decline in carbonate production threatens coral reef growth. Nat Commun 4:1402-1407

Roff G, Mumby PJ (2012) Global disparity in the resilience of coral reefs. Trends Ecol Evol 27:404-413

Editorial responsibility: Peter Edmunds, Northridge, California, USA
Schutte VGW, Selig ER, Bruno JF (2010) Regional spatiotemporal trends in Caribbean coral reef benthic communities. Mar Ecol Prog Ser 402:115-122

Torres R, Chiappone M, Geraldes F, Rodriguez Y, Vega M (2001) Sedimentation as an important environmental influence on Dominican Republic reefs. Bull Mar Sci 69: 805-818

Weil E, Smith G, Gil-Agudelo DL (2006) Status and progress in coral reef disease research. Dis Aquat Org 69:1-7

Yoshioka PM, Yoshioka BB (1989) Effects of wave energy, topographic relief and sediment transport on the distribution of shallow-water gorgonians of Puerto Rico. Coral Reefs 8:145-152

Zuur AF, Ieno EN, Walker NJ Saveliev AA, Smith GM (2009) Mixed effects models and extensions in ecology with R. Springer, New York, NY

Submitted: December 22, 2014; Accepted: April 30, 2015

Proofs received from author(s): June 4, 2015 